\title{
Risk-Constrained Optimal Chiller Loading Strategy Using Information Gap Decision Theory
}

\author{
Er Shi ${ }^{1}$, Farkhondeh Jabari ${ }^{2}$, Amjad Anvari-Moghaddam ${ }^{3, *} \mathbb{C}$, Mousa Mohammadpourfard ${ }^{4}(\mathbb{D}$ \\ and Behnam Mohammadi-ivatloo ${ }^{2}$ \\ 1 School of Energy and Power Engineering, Changsha University of Science and Technology, \\ Changsha 410114, China; shier@csust.edu.cn \\ 2 Faculty of Electrical and Computer Engineering, University of Tabriz, Tabriz 5166616471, Iran; \\ f.jabari@tabrizu.ac.ir (F.J.); bmohammadi@tabrizu.ac.ir (B.M.-i.) \\ 3 Department of Energy Technology, Power Electronic Systems, 9220 Aalborg, Denmark \\ 4 Faculty of Chemical and Petroleum Engineering, University of Tabriz, Tabriz 5166616471, Iran; \\ mohammadpour@tabrizu.ac.ir \\ * Correspondence: aam@et.aau.dk
}

Received: 14 February 2019; Accepted: 8 May 2019; Published: 10 May 2019

\begin{abstract}
This paper presents a novel framework for economic cooling load dispatch in conventional water-cooled chillers. Moreover, information gap decision theory (IGDT) is applied to the optimal chiller loading $(\mathrm{OCL})$ problem to find the optimum operating point of the test system in three decision-making modes: (a) risk-neutral approach, (b) risk-aversion or robustness approach, and (c) risk-taker or opportunistic approach. In the robustness mode of the IGDT-based OCL problem, the system operator enters a desired energy cost value in order to find the most appropriate loading points for the chillers so that the total electricity procurement cost over the study horizon is smaller than or equal to this critical value. Meanwhile, the cooling load increase is maximized to the highest possible level to find the most robust performance of the benchmark grid with respect to the overestimated load. Similarly, the risk-taker optimization method finds the on/off status and the partial load ratio (PLR) of the chillers in order to keep the total energy cost as low as the given cost function. In addition, the minimum value of cooling load decrease can be found while satisfying the refrigeration capacity of the chiller and the load-generation balance constraint. Thus, a mixed-integer non-linear programming problem is solved using the branch and reduce optimization (BARON) tool of the generalized algebraic mathematical modeling system (GAMS) for a five-chiller plant, to demonstrate that IGDT is able to find a good solution in robustness/risk-taker OCL problem.
\end{abstract}

Keywords: optimal chiller loading (OCL); uncertain cooling demand; information gap decision theory (IGDT); mixed-integer non-linear programming problem (MINLP)

\section{Introduction}

In summer, different end users, such as residential and commercial sectors, consume more electricity for building space cooling. This may lead to an energy crisis and cascading power outages $[1,2]$. Therefore, the economic operation of electrical air conditioners is important to reduce the energy demand of interconnected power systems. The optimal short-term scheduling of multiple-chiller systems is a cost-effective tool to minimize the total energy cost and power consumption of multiple-chiller plants [3,4]. The main objective of the economic chiller dispatch problem is to minimize the power consumption of the chillers while satisfying the cooling load-generation balance constraint and the refrigeration capacity of the chiller units $[5,6]$. The partial load ratio, refrigeration production, and electrical power consumption of the chillers have been selected as the decision variables of the 
optimization problem. Moreover, the binary variables that show the on or off status of the chillers are used to determine which ones are turned on at each operating time interval. The variable climatic conditions affect the building cooling demand, the optimum value of the partial load ratios (PLRs), and the cooling capability of the chillers, as well as their power consumption [7]. Therefore, the uncertainties associated with the cooling load should be modeled by short-term scheduling of electrical air conditioners [8,9].

Recently, researchers have presented fast optimization algorithms for solving the optimal chiller loading (OCL) problem. In [10], the branch and bound method was proposed to find the best values of the PLR of the chillers and minimize the power consumption of the water coolers. Chang et al. [11] proved that the gradient method achieves the optimum scenario with less calculation time and better objective function than the Lagrangian approach. The authors of [12] demonstrated that if the particle swarm optimization (PSO) is integrated with the neural networks, the power consumption of the chillers will be $18 \%$ less than that achieved by linear regression and the equal loading distribution method. The simulated annealing method, which is used for heating a specific metal to its melting temperature, reducing shape defects, and cooling the modified metal, provides more accurate solutions than the Lagrangian approach [13]. Coelho and Mariani [14] solved the OCL problem by using the Gaussian distribution function coupled with the firefly search algorithm. The firefly search algorithm is a well-known search strategy that was inspired by the behavior of fireflies, which attract mating partners based on light intensities. In this model, it is assumed that all fireflies except one are of the same sex and only the firefly of the different sex can be attracted by the others. Other search algorithms, such as evolution strategy [15], teaching learning procedure [16], cuckoo search algorithm [17], differential evolution method [18], exchange market strategy [19,20], and basic open-source non-linear mixed-integer programming [21], provide global optimal solutions with a lower computational burden in less time than the genetic algorithm [22,23]. Lo et al. [24] introduced a novel OCL strategy based on non-linear ripple weight indices and self-adaption repulsion factors, known as the ripple bee swarm optimization technique, but invasive weed optimization [25] is able to find better operating points in the three test systems than those obtained by this technique. Saeedi et al. [26] applied an interval robust optimization algorithm to the OCL problem in order to model the uncertainty of the cooling demand. Minimum and maximum forecasted values of cooling load over a 24-h study horizon were considered in order to minimize the total electricity requirement of a three-chiller standard grid. The partial load ratio, refrigeration production, and power consumption of the chillers in three scenarios-(a) minimum cooling load profile, (b) forecasted demand, and (c) maximum load level-were compared. Recent studies on the possible use of thermoacoustic refrigerators have provided quite significant results, which may lead to a considerable reduction in environmental pollutants and, in the future, a reduction in costs [27] due to the use of new smart-window technologies that reduce the cooling load [28].

Different search methods have been proposed for solving the OCL problem and saving energy in air conditioning systems, but the uncertainty of the cooling demand has only been discussed in [26]. Two consecutive intervals have been considered for modeling the underestimated and overestimated cooling loads in the robust optimization approach. Meanwhile, information gap decision theory (IGDT) could be applied to economic dispatch problems in order to model both risk-aversion or robustness and risk-taker or opportunistic aspects of risk-constrained OCL strategy. This paper implements the IGDT algorithm on a benchmark five-chiller plant in order to solve a mixed-integer non-linear programming problem with a generalized algebraic mathematical modeling system (GAMS). In the risk-aversion OCL problem, the system operator enters a critical cost value. The cooling load increase is then maximized in such a way that the sum of the refrigeration production of the chillers is higher than or equal to the overestimated cooling demand, and the daily energy cost of the test system is smaller than the given cost function. In other words, the total electricity cost over the study horizon is not considered to be the objective function. It is restricted so that it is smaller than the critical cost function. The maximum value of the cooling demand increase that can be satisfied by chillers is then calculated as the objective function. In the risk-taker or opportunistic decision-making process, 
the minimum value of the cooling load decrease is calculated in order to reduce the total energy cost so that it is as low as the given cost function. The refrigeration capacity constraints of the chillers and load-generation balance criterion are also modeled in robustness and risk-taker modes. The on/off status, partial load ratio, cooling generation, and electricity consumption of each chiller are selected as the decision variables that are found in the base case study and the robustness and opportunistic OCL problem. In all reviewed works, the total power consumption of the chiller plants was minimized as the objective function, but real-time electricity prices should be considered for minimization of the total energy cost of multi-chiller systems. The novel contributions of this paper can be summarized as follows:

- The IGDT method was applied to the OCL problem to model the uncertainty of the cooling demand.

- The robustness or risk-aversion decision-making approach was used for maximizing the value of the cooling load increase while minimizing the daily energy cost so that it was as low as the critical energy cost.

- The opportunistic or risk-taker OCL strategy was used to find the best operating point of the chillers so that the minimum value of the cooling load decrease that results in target cost saving was found.

\section{Proposed IGDT-Based OCL Strategy}

Figure 1 shows the single-line diagram of a conventional multi-chiller plant. In this system, the total electricity cost is minimized over the T-hour study horizon, as given by Equation (1), where $\lambda_{t}$ and $P_{i}^{t}$ are the electricity price and the power consumption of chiller $i$ at operating time interval $t$, which can be calculated from Equations (2)-(4), where, $u_{i}^{t}$ is a binary decision variable that is equal to 1 if the $i^{\text {th }}$ chiller is on at hour $t$; otherwise, it will be 0 . Based on Equation (3), the partial load ratio of chiller $i$ is selected as another decision variable and represents the cooling capacity constraint. As is evident from Equation (4), when chiller $i$ is on at hour $t$, its electrical power consumption depends on the constant coefficients $a_{i}, b_{i}, c_{i}$, and $d_{i}$ and its cooling production; otherwise, it will be 0 . Equation (5) demonstrates that the refrigeration capability of the chillers should be equal to or larger than the cooling demand at time interval $t$. Note that $C L_{t}$ and $R T_{i}$ denote the cooling load at hour $t$ and the refrigeration capacity of chiller $i$, respectively [26].

$$
\begin{aligned}
& \text { Energy cost }=\sum_{t=1}^{T} \sum_{i=1}^{N}\left(\lambda_{t} \times P_{i}^{t}\right) \\
& u_{i}^{t}=\left\{\begin{array}{ll}
0 & \text { if chiller } i \text { is off } \\
1 & \text { if chiller } i \text { is on }
\end{array}\right\} \\
& P L R_{i}^{t}=\left\{\begin{array}{cl}
0 & \text { if chiller } i \text { is off } \\
\frac{\text { Cooling load of chiller } i \text { at time } t}{\text { Refrigeration capacity of chiller } i}=\text { rand } & \text { if chiller } i \text { is on }
\end{array}\right\} \\
& P_{i}^{t}=\left\{\begin{array}{cc}
0 & \text { if } u_{i}^{t}=0 \\
a_{i}+b_{i} P L R_{i}^{t}+c_{i}\left(P L R_{i}^{t}\right)^{2}+d_{i}\left(P L R_{i}^{t}\right)^{3} & \text { if } u_{i}^{t}=1
\end{array}\right\} \\
& C L_{t} \leq \sum_{i=1}^{N} P L R_{i}^{t} \times R T_{i}
\end{aligned}
$$




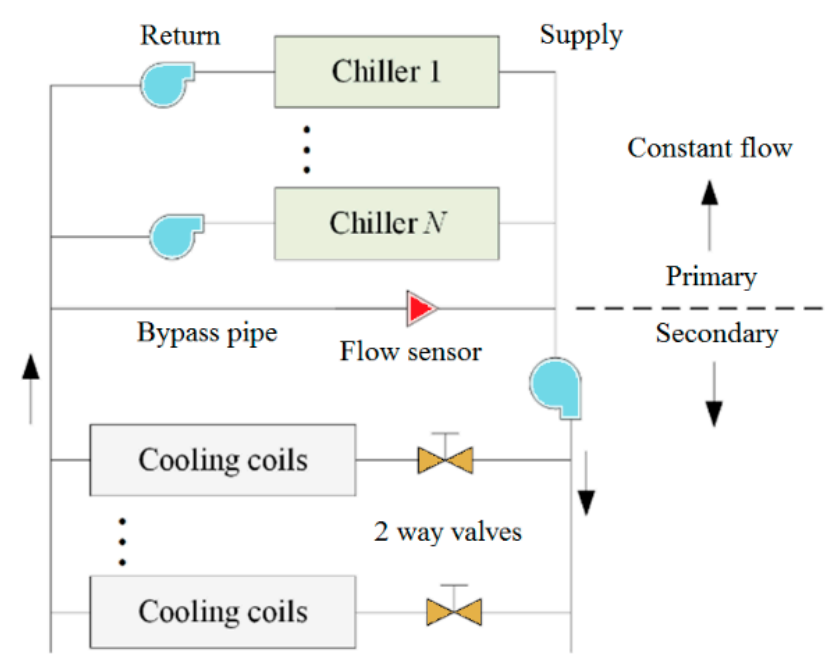

Figure 1. Single-line diagram of a conventional multi-chiller plant.

\subsection{IGDT-Based OCL Problem}

The main objective of the IGDT approach is to maximize the horizon of the cooling demand uncertainty, while minimizing the daily energy cost of the multiple-chiller plant to be as low as the given value. The IGDT method enables the system operator to make the appropriate and most cost-effective decisions regarding the probable fluctuations of the cooling demand. In the economic dispatching of chiller units, the cooling load may behave adversely and lead to a higher energy cost or it may behave desirably and lead to a lower electricity cost. In other words, the IGDT strategy assesses the robustness and opportunistic aspects of the air conditioning process by modeling the unexpected variations of the cooling load using three components: (a) system model, (b) performance requirement, and (c) uncertainty model.

\subsubsection{System Model}

It is presumed that the cooling demand, $C L_{t}$, is an uncertain parameter, and it may be increased or decreased at each time interval $t$. Moreover, the input-output model of the multi-chiller system is shown as the energy cost function $F\left(x_{i}^{t}, C L_{t}\right)$, where $x_{i}^{t}$ denotes the decision variables of the optimization problem, which include the on/off status, partial load ratio, cooling production, and electrical power consumption of $i^{\text {th }}$ chiller at hour $t$. The daily energy cost function, $F\left(x_{i}^{t}, C L_{t}\right)$, should be minimized to be as low as possible.

\subsubsection{Performance Requirement}

The expectations of the system operator regarding the energy cost function are evaluated using the robustness and opportunistic strategies, Equations (6) and (7), respectively. According to Equation (6), the robust optimization problem is formulated with an aim to maximize the uncertainty variable, $\alpha$, while the energy cost is less than the given cost, $F_{k}$. The uncertainty variable, $\alpha$, is maximized as per Equation (8). The system operator makes the robustness decision with less sensitivity to the variations of the uncertain parameter, $C L_{t}$. Moreover, the energy cost over the study time interval $T$ is smaller than the predefined critical cost $F_{k}$. The robustness function, $\hat{\alpha}$, investigates how robust the multi-chiller system is against the possible increase in cooling demand. A risk-taker decisionmaker requests a lower energy cost by implementing the opportunity mode of the IGDT algorithm. As formulated by Equation (9), the variable $\beta$ is the minimum value of $\alpha$ with the aim of achieving lower costs for the decision variables, $x_{i}^{t}$. Note that $F_{w}$ represents the maximum cost of the opportunity strategy, which is determined by the system operator, for paying less under the favorable changes of the uncertain cooling demand, $C L_{t}$. 
$\hat{\alpha}=\operatorname{Max}_{\alpha}\{$ Maximum energy cost is lower than a predefined critical cost $\}$

$\hat{\alpha}=\operatorname{Max}_{\alpha}\{$ Maximum energy cost is lower than a predefined critical cost $\}$

$$
\begin{aligned}
& \hat{\alpha}\left(x_{i}^{t}, F_{k}\right)=\operatorname{Max}_{\alpha}\left\{\alpha: \operatorname{Max}_{x_{i}^{t}} F\left(x_{i}^{t}, C L_{t}\right) \leq F_{k}\right\} \\
& \hat{\beta}\left(x_{i}^{t}, F_{w}\right)=\operatorname{Min}_{\beta}\left\{\alpha: \operatorname{Min}_{x_{i}^{t}} F\left(x_{i}^{t}, C L_{t}\right) \leq F_{w}\right\}
\end{aligned}
$$

\subsubsection{Uncertainty Model in Risk-Aversion or Robustness Mode}

The robustness variable, $\hat{\alpha}\left(x_{i}^{t}, F_{k}\right)$, is defined for the risk-aversion decision-making approach and evaluates the greatest value of the uncertainty variable, $\alpha$, when the maximum cost is smaller than the predefined cost, $F_{k}$. The larger $\hat{\alpha}\left(x_{i}^{t}, F_{k}\right)$ indicates higher robustness against uncertainty. Therefore, $\hat{\alpha}\left(x_{i}^{t}, F_{k}\right)$ will increase as $F_{k}$ increases, and vice versa. The uncertain cooling demand can be calculated by Equation (10). The increasing rate of the cooling load causes an increase in the energy cost function, which is evident from Equation (10). According to Equation (11), the objective is to maximize $\alpha$ for the given critical cost, $F_{k}$. The parameter $C L_{t}^{0}$ represents the forecasted cooling demand at operating time interval $t$.

$$
\begin{gathered}
C L_{t}=(1+\alpha) \times C L_{t}^{0} \\
\hat{\alpha}\left(Q_{i}^{t}, P_{i}^{t}, F_{k}\right)=\operatorname{Max}_{\alpha}\left\{\alpha: \operatorname{Max}_{Q_{i}^{t}, P_{i}^{t}} \sum_{t=1}^{T} \sum_{i=1}^{N}\left(\lambda_{t} \times P_{i}^{t}\right) \leq F_{k}\right\}
\end{gathered}
$$

\subsubsection{Uncertainty Model in Opportunistic Decision-Making Strategy}

The opportunity function, $\hat{\beta}\left(x_{i}^{t}, F_{w}\right)$, assesses the feasibility of the lower costs. Therefore, a small value of $\hat{\beta}\left(x_{i}^{t}, F_{w}\right)$ is desirable. According to Equation (12), the opportunity variable is the lowest value of $\alpha$ for minimization of energy cost as low as $F_{w}$. Therefore, it is expected that $\hat{\beta}\left(x_{i}^{t}, F_{w}\right)$ increases with the reduction of $F_{w}$ for the energy cost minimization approach as in Equations (13) and (14). As expected from Equation (13), the decreasing rate of the cooling demand causes a decrease in electricity cost.

$$
\begin{gathered}
\hat{\beta}\left(x_{i}^{t}, F_{w}\right)=\operatorname{Min}_{x_{i}^{t}} \hat{\alpha}\left(x_{i}^{t}, F_{w}\right) \\
C L_{t}=(1-\alpha) \times C L_{t}^{0} \\
\hat{\beta}\left(Q_{i}^{t}, P_{i}^{t}, F_{k}\right)=\operatorname{Min}_{\alpha}\left\{\alpha: \operatorname{Min}_{Q_{i}^{t}, P_{i}^{t}} \sum_{t=1}^{T} \sum_{i=1}^{N}\left(\lambda_{t} \times P_{i}^{t}\right) \leq F_{w}\right\}
\end{gathered}
$$

\section{Numerical Result and Discussions}

A mixed-integer non-linear program (MINLP) was developed by GAMS software [29] and was solved using a branch and reduce optimization navigator (BARON) tool [30]. A benchmark multi-chiller system with two 550 and three 1000 RT chillers [31] was used for simulations. The power consumption coefficients and the cooling capacity of the chillers are presented in Table 1 . The forecasted value of the cooling load over a 24-h study horizon [31] is illustrated in Figure 2. The hourly variations of the electricity prices [32] are shown in Figure 3. 
Table 1. Power consumption coefficients and cooling capacity of chillers.

\begin{tabular}{cccccc}
\hline Chiller & $\boldsymbol{a}_{\boldsymbol{i}}$ & $\boldsymbol{b}_{\boldsymbol{i}}$ & $\boldsymbol{c}_{\boldsymbol{i}}$ & $\boldsymbol{d}_{\boldsymbol{i}}$ & $\boldsymbol{Q}_{\boldsymbol{i}}^{\text {max }}(\mathrm{RT})$ \\
\hline 1 & 57.2 & 329.73 & 0.05 & 7.85 & 550 \\
2 & 50.09 & 419.28 & -123.8 & 76.36 & 550 \\
3 & -76.29 & 1226.94 & -709.37 & 296.93 & 1000 \\
4 & -72.56 & 1100.42 & -145.77 & -137.1 & 1000 \\
5 & -186.18 & 1817.08 & -1755.59 & 847.43 & 1000 \\
\hline
\end{tabular}

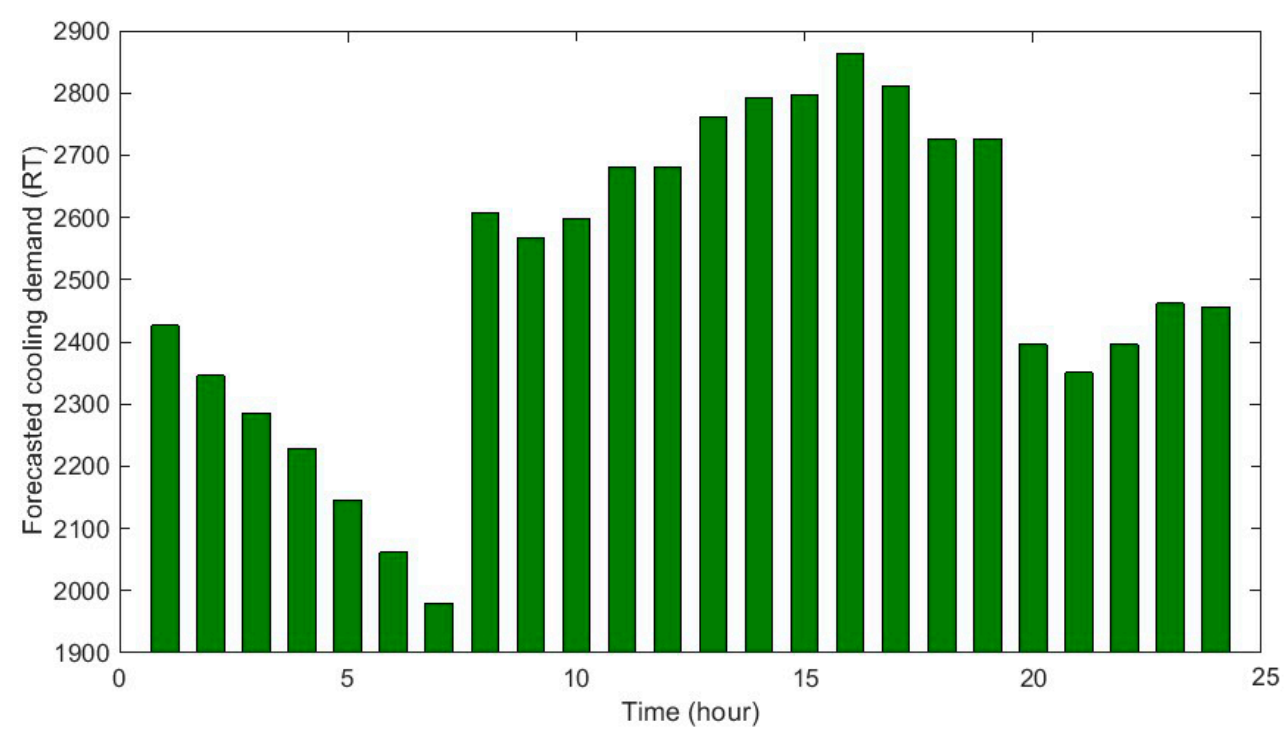

Figure 2. Forecasted value of cooling demand over a sample 24-h time interval.

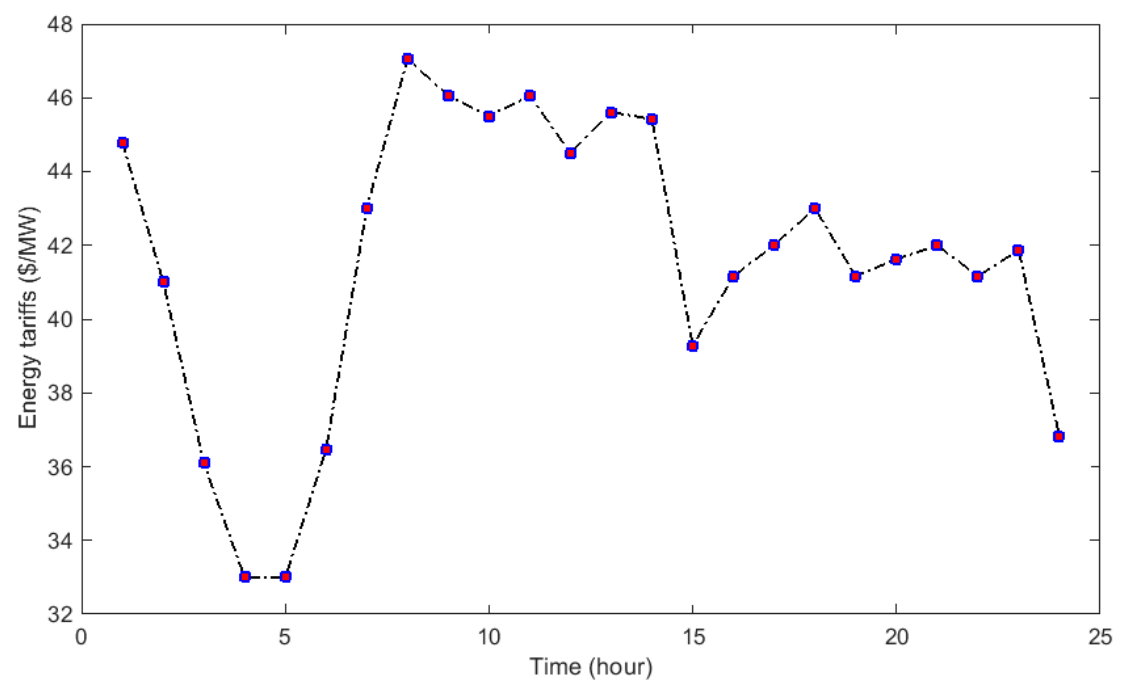

Figure 3. Hourly variations of energy rates.

First, the robustness OCL problem was solved using the GAMS optimization software in conjunction with the different values of the critical energy costs. The risk-aversion optimization problem was performed on the test system, taking Equations (1)-(5), (10), and (11) into consideration. The system operator then determined the value of the known parameter $F_{k}$ for 12 iterations $(k=12)$. As mentioned in Section 2.1.3, the main objective of the robustness mode at each scenario $k$ was to maximize the percentage of the cooling load increase by increasing $\alpha$ in such a way that the maximum value of the daily energy cost is smaller than or equal to the predefined critical cost $F_{k}$. Meanwhile, the cooling capacity of the chillers was satisfactory at each solution. In addition, the total refrigeration production of the chiller units was more than or equal to the overestimated cooling demand, or 
$(1+\alpha) \times C L_{t}^{0}$. Figure 4 shows the optimum value of the cooling demand increase at each iteration of the robustness economic dispatch problem. The vertical axis represents the predefined critical energy cost, $F_{k}$, at each iteration $k$. The horizontal axis refers to the maximum value of the cooling load increase, which is obtained by solving the robust short-term scheduling problem. As expected from Equations (3)-(5), (10), and (11), when the building cooling load increased, the value of the refrigeration production of the chillers increased, as did the electrical power consumption of the chillers. Figure 4 shows the optimum value of the cooling load increase at each scenario of the robust economic dispatch problem. It is clear that the daily electricity cost increased, a result which is to be expected as per Equation (1). In the opportunistic optimal cooling energy procurement strategy, the target energy cost, $F_{w}$, is lower than that obtained from solving the base case study (Equations (1)-(5)) without considering the uncertainty of the cooling load. In other words, the system operator wants the daily electricity purchasing cost to be smaller than the energy cost of the multi-chiller system under $\alpha=\beta=0$ or the base optimization problem. The system owner wants to reduce the daily energy cost of the five-chiller plant so that it is as low as the target energy cost, $F_{w}$. Hence, the minimum value of the cooling load decrease, which reduces the energy cost to predefined values $F_{w}$, must be found by solving the optimization problem (Equations (1)-(5), (13) and (14)). As shown in Figure 5, eight scenarios were considered for the risk-taker decision-making approach $(w=8)$. As expected from Equations (5) and (13) and displayed in Figure 5, when the cooling demand decreased, the value of the cooling production of the chillers also decreased. Therefore, they consumed less electrical power while supplying this underestimated cooling demand. The day-ahead energy cost was also reduced, as predicted by Equations (1)-(4).

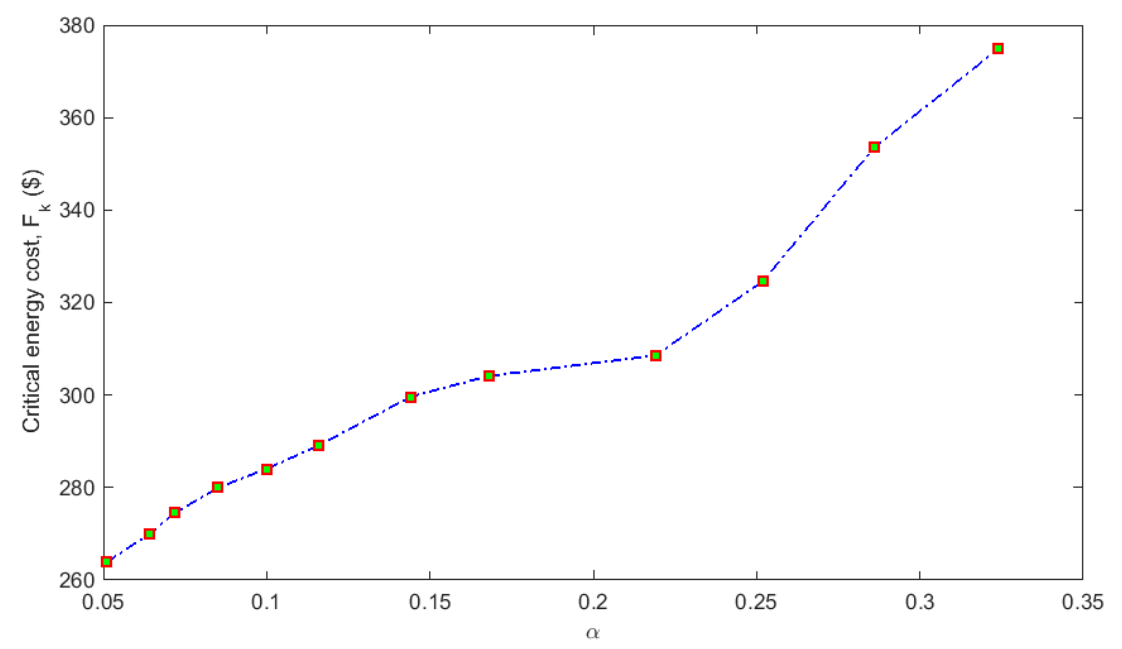

Figure 4. The optimum value of the cooling load increase at each scenario of the robust economic dispatch problem.

Figures 6 and 7 show the daily electricity consumption of the chillers in three cases: (a) risk-neutral, (b) risk-aversion or robustness OCL problem, and (c) risk-taker or opportunistic economic dispatch process. As mentioned before, when the values of the robustness and opportunity factors are equal to zero, $\alpha=\beta=0$ and the base OCL problem is solved in accordance with the forecasted cooling load profile (Figure 2). Hence, the daily electricity cost will be equal to $\$ 254.5$ as a result of $6097.69 \mathrm{~kW}$ power consumption by the chillers, as seen in Figures 6 and 7. If the system owner wants to pay the higher energy costs and procure greater electrical power for the chillers, the maximum value of the cooling demand increase can be found, as shown in Figure 6. This figure enables the system operator to know how much the cooling demand can be increased to meet the specific value of the energy cost. It is also possible to find the minimum value of the cooling load decrease in order to save the electrical power a certain value, as demonstrated in Figure 7. 


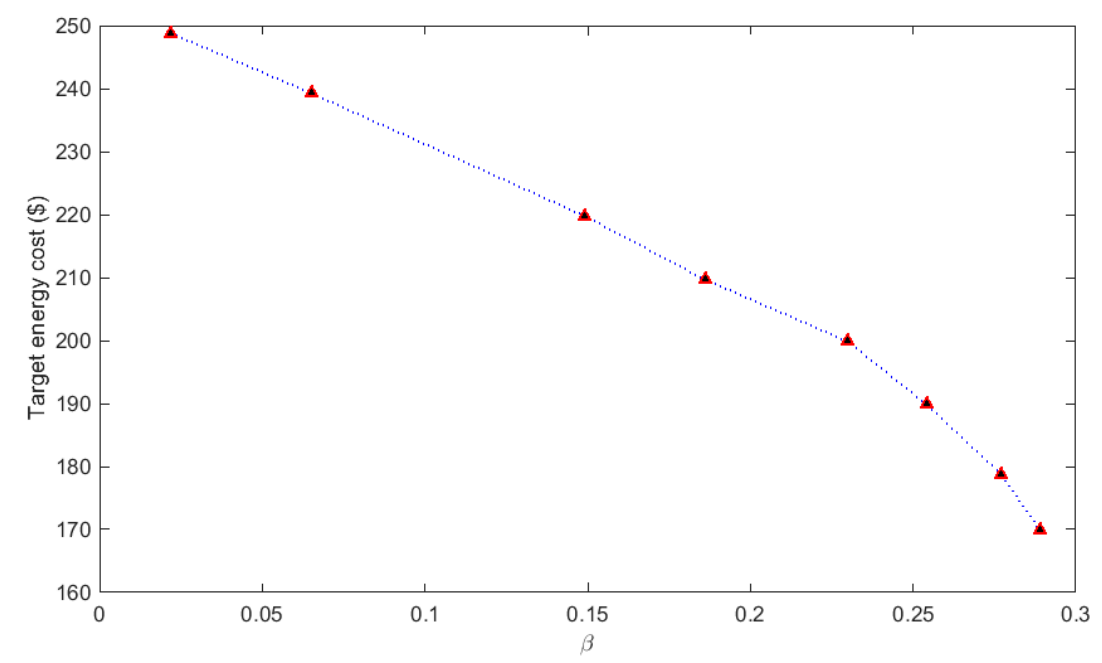

Figure 5. The minimum value of the cooling load decrease at each iteration of the opportunistic optimal chiller loading (OCL) strategy.

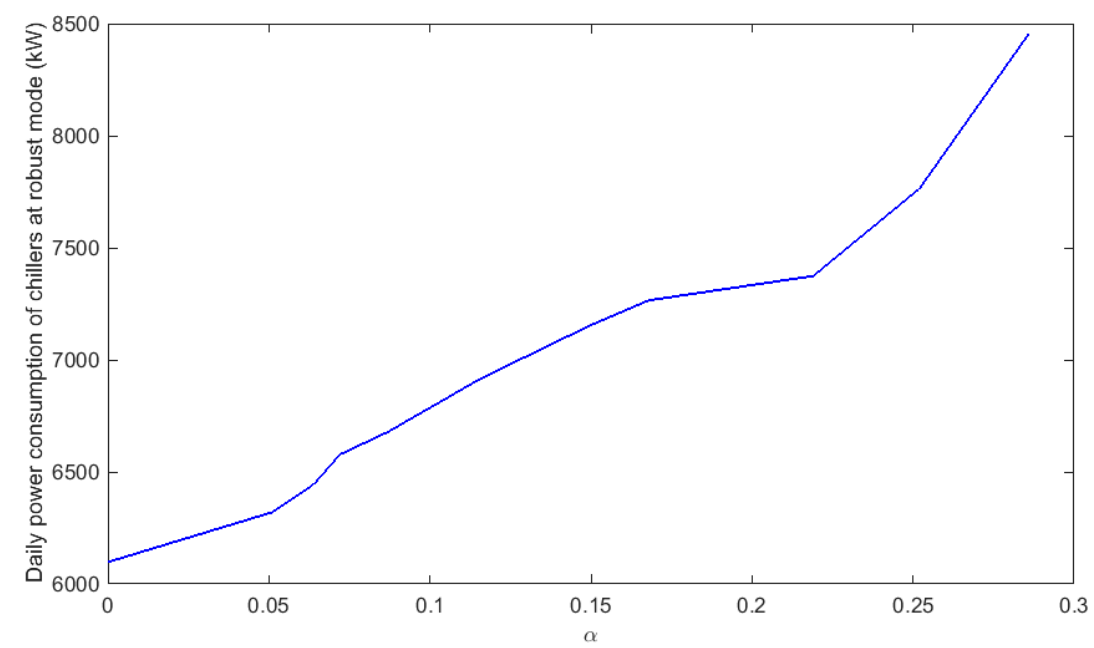

Figure 6. Daily power consumption of chillers versus $\alpha$.

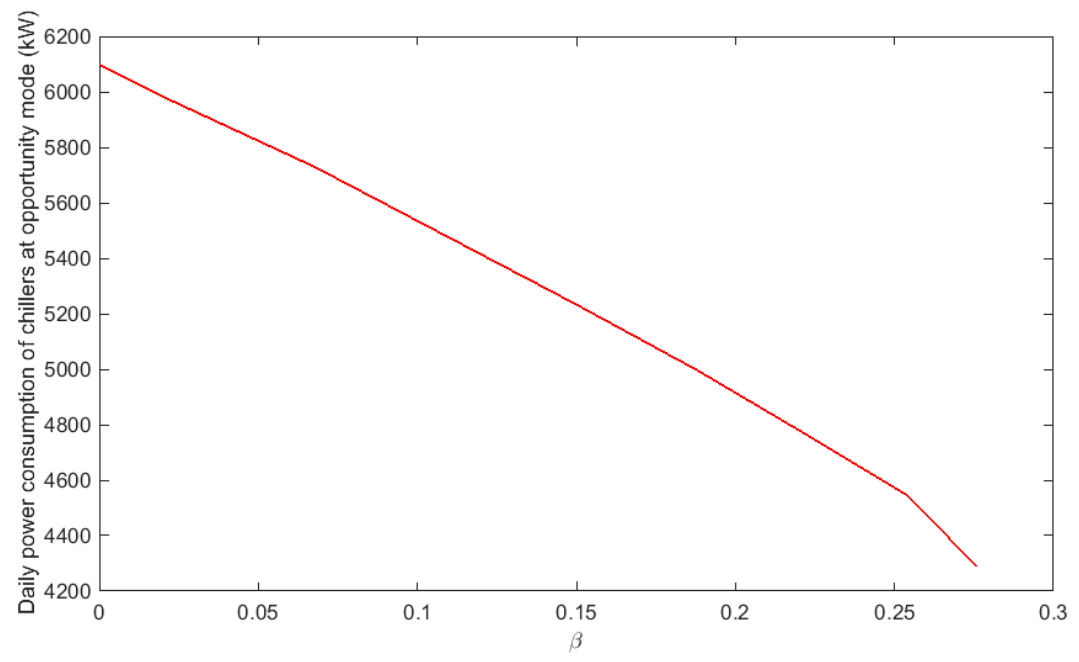

Figure 7. Daily energy requirement of chiller units versus $\beta$.

The PLR cooling generation and the electrical power consumption of the chillers in the three cases are shown in Figure $8 \mathrm{a}-\mathrm{c}$, respectively. Figure 8a depicts the PLRs of the chillers versus the 
critical $\left(F_{k}\right)$ and target $\left(F_{w}\right)$ costs. The orange line marks the boundary between the opportunistic and robustness modes. At hour 7, the PLR and the power consumption of chiller 2 will be equal to zero in all robustness and risk-taker scenarios. The optimization problem detects that if chiller 2 is off and does not operate at hour 7 , the total energy cost of the system will be less than when it turns on at this hour. It may be economic to turn on chiller 2 at hours with different cooling demand values. Figure 8 demonstrates how the cooling demand changes at hour 7 , as well as how much electrical power is consumed by the chillers to supply this value. This information can be utilized when it comes to making robustness/opportunistic decisions with respect to the cooling load increase/decrease. Figure 8 also allows the system operator to see the value of the power consumption of the chillers and daily energy cost when the cooling load at hour 7 changes from 1400 to 2600 RT. As seen in Figure 2, the forecasted cooling demand at hour 7 in the deterministic or risk-neutral optimization problem, without considering the uncertainty of the cooling demand, is equal to $1979 \mathrm{RT}$, which is shown with a vertical line. If the cooling demand is less than 1979 RT (opportunistic zone), the system owner gains more energy cost savings from the underestimated cooling load. In the same manner, when the cooling demand increases from 1979 RT (robust mode), the daily energy cost increases. Hence, the value of the power consumption of the chillers will change according to the left and right sides of the vertical boundary line, designated as "Opportunity" and "Robust". For example, if the opportunity factor is equal to 0.289 and the cooling demand is $(1-0.289) \times 1979=1407$ RT in opportunistic operating mode, the value of the power consumption of chillers $1,3,4$, and 5 will be equal to 65 , 68,107 , and $0 \mathrm{~kW}$, respectively. However, if the cooling demand at this hour increases to $1431 \mathrm{RT}$, their power consumption will change to $0,68,0$, and $101 \mathrm{~kW}$, respectively. Even though the cooling demand increases, it will still be more economic to turn off chillers 1 and 4 and turn on chiller 5 . Similarly, if the cooling demand increases from 1979 RT in the deterministic or risk-neutral optimization problem to $2478 \mathrm{RT}\left(\alpha=0.252, C L_{t=7}=(1-0.252) \times 1979=2478\right)$ in the robust economic dispatch strategy, the electricity consumption of chiller 1 changes from 0 to $65 \mathrm{~kW}$. The IGDT-based uncertainty modeling approach enables the operator to make appropriate decisions in order to optimize the system's operation with respect to possible changes in cooling load. Similar analysis can be considered for other hours with different values of cooling load.

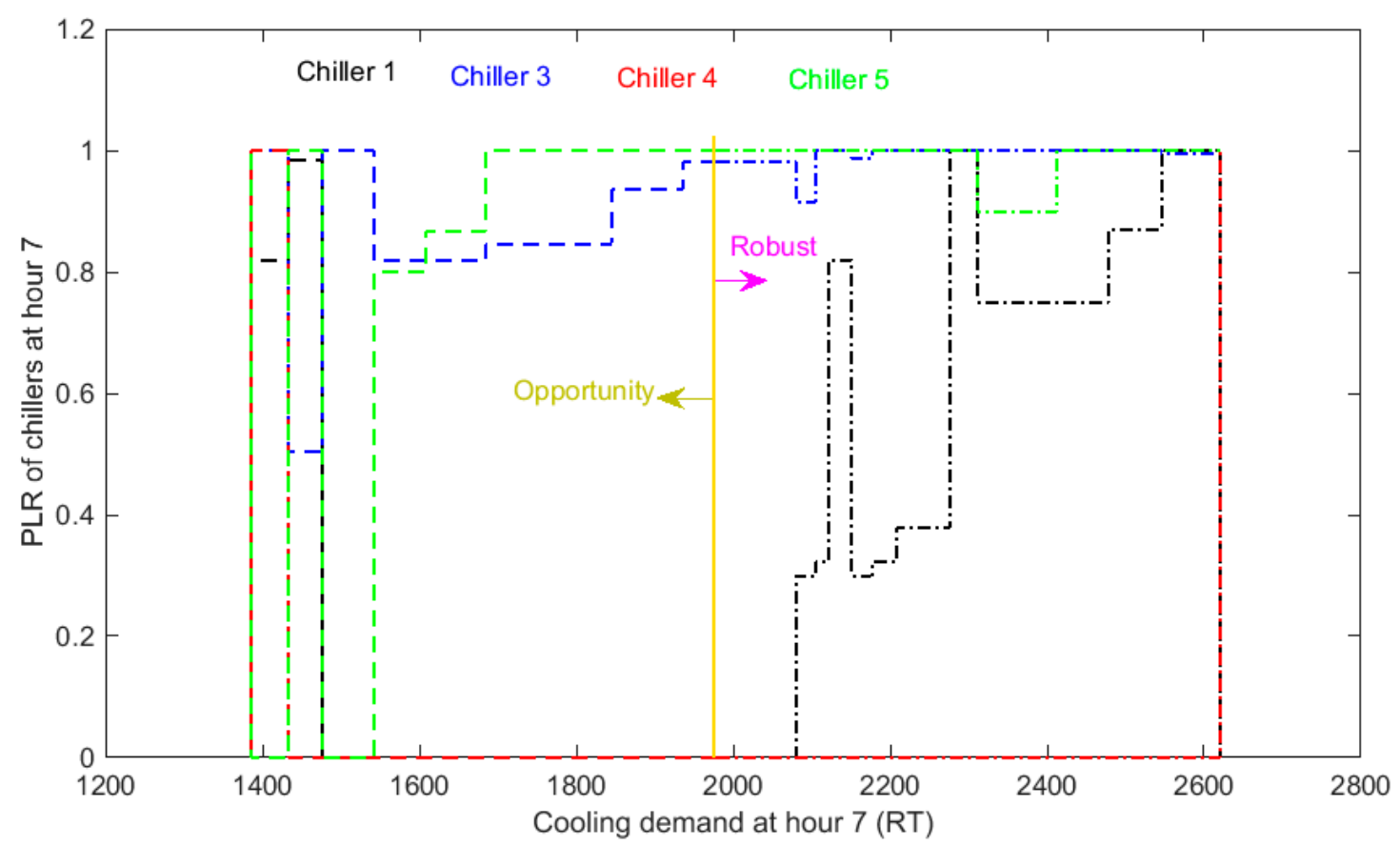

(a) Partial load ratio (PLR) of chillers at hour 7.

Figure 8. Cont. 


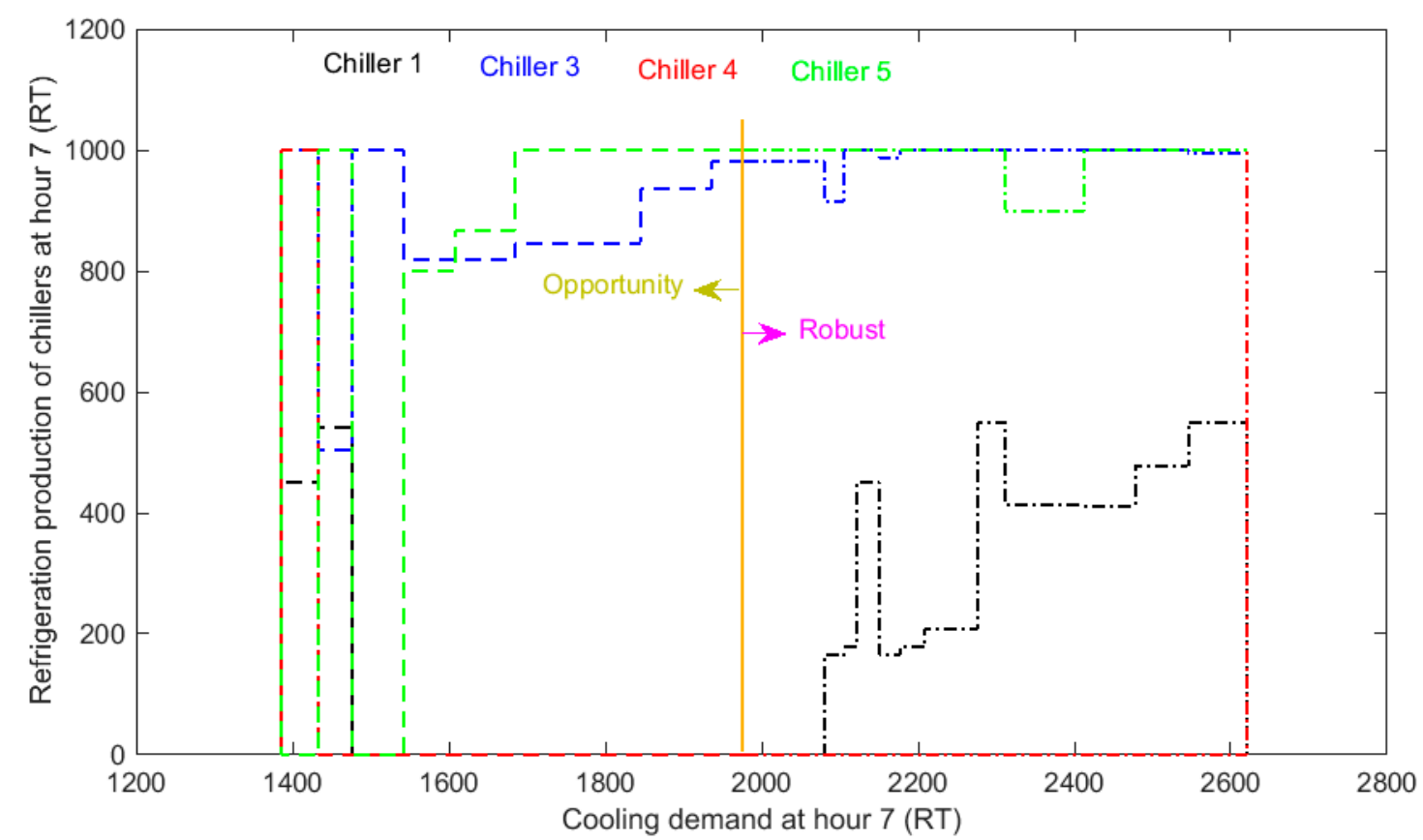

(b) Refrigeration production of chillers at hour 7 .

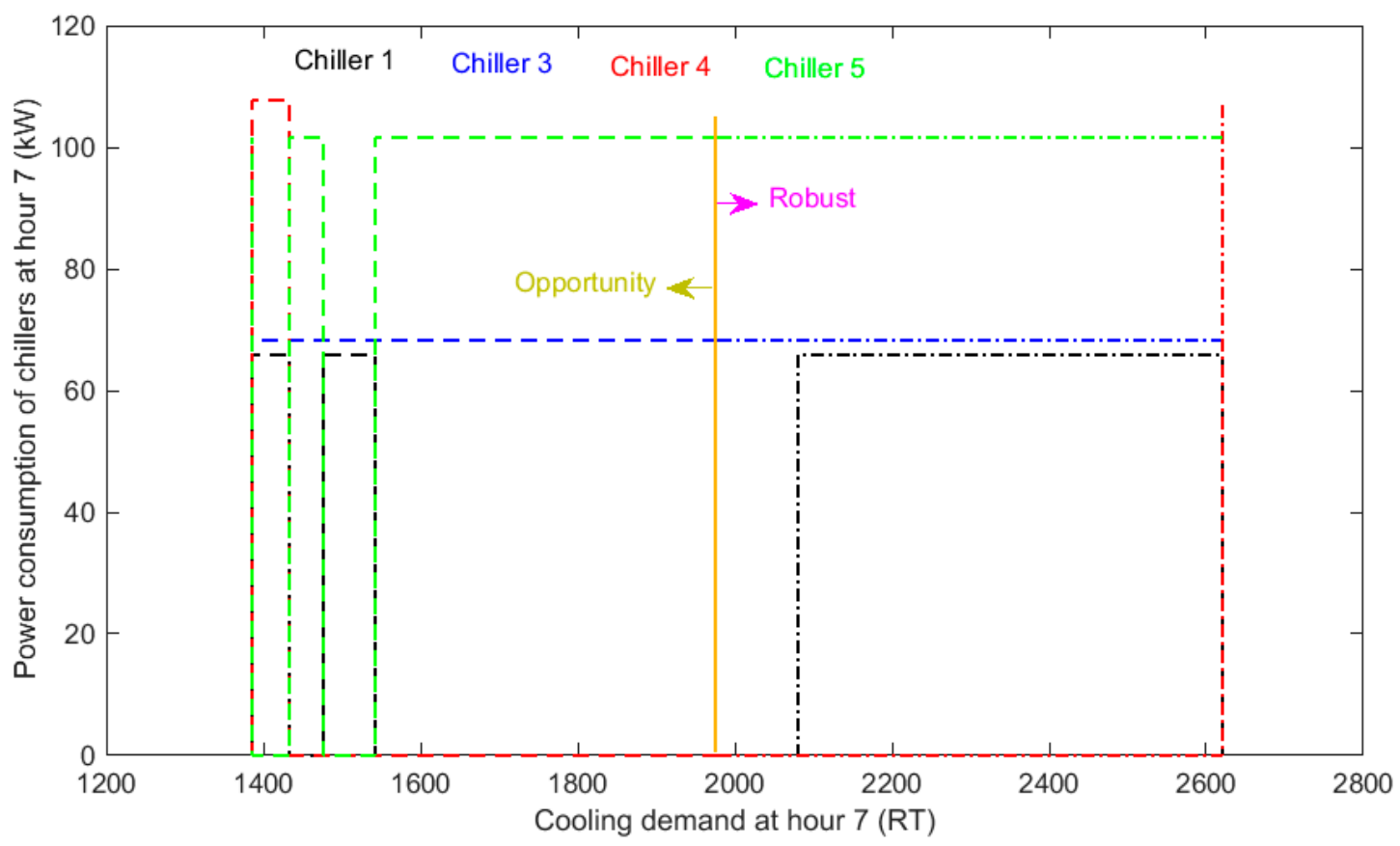

(c) Electrical power consumption of chillers at hour 7.

Figure 8. The optimal operating points of the chillers at hour 7 (a) PLR, (b) cooling generation and (c) power consumption.

\section{Conclusions}

This paper proposed a novel framework for modeling the uncertain nature of cooling demand in the day-ahead optimal scheduling of multiple-chiller systems. The information gap decision theory approach was used for finding the robustness or risk-aversion solution against the maximum cooling load increase. Moreover, the opportunity for cost and energy saving under the minimum value of the load decrease was maximized. The presented model was shown to enable a system operator to input the desired energy cost parameter and minimize the daily energy cost to this critical value and also to determine the maximum cooling demand increase in the robustness model. In addition, a risk-taker 
decisionmaker can schedule the daily refrigeration generation patterns of the chillers so that the daily energy cost of the plant is smaller than the predefined target cost. The minimum value of the cooling demand can also be calculated and reduced for favorable cost saving.

Author Contributions: Conceptualization, F.J.; methodology, B.M.-i; software, F.J.; validation, M.M.; formal analysis, F.J.; investigation, M.M.; resources, A.A.-M. and B.M.-i; writing-original draft preparation, F.J.; writing-review and editing, A.A.-M. and E.S.; visualization, E.S.; and supervision, B.M.-i and M.M.

Conflicts of Interest: The authors declare no conflict of interest.

\section{References}

1. Zheng, Z.-X.; Li, J.-Q.; Duan, P.-Y. Optimal chiller loading by improved artificial fish swarm algorithm for energy saving. Math. Comput. Simul. 2019, 155, 227-243. [CrossRef]

2. Sulaiman, M.H.; Ibrahim, H.; Daniyal, H.; Mohamed, M.R. A new swarm intelligence approach for optimal chiller loading for energy conservation. Procedia Soc. Behav. Sci. 2014, 129, 483-488. [CrossRef]

3. Wang, Y.; Jin, X.; Du, Z.; Zhu, X. Evaluation of operation performance of a multi-chiller system using a data-based chiller model. Energy Build. 2018, 172, 1-9. [CrossRef]

4. Powell, K.M.; Cole, W.J.; Ekarika, U.F.; Edgar, T.F. Optimal chiller loading in a district cooling system with thermal energy storage. Energy 2013, 50, 445-453. [CrossRef]

5. Wang, Y.; Jin, X.; Shi, W.; Wang, J. Online chiller loading strategy based on the near-optimal performance map for energy conservation. Appl. Energy 2019, 238, 1444-1451. [CrossRef]

6. Chang, Y.-C. Optimal chiller loading by evolution strategy for saving energy. Energy Build. 2007, 39, $437-444$. [CrossRef]

7. Hallegatte, S. Strategies to adapt to an uncertain climate change. Glob. Environ. Chang. 2009, 19, $240-247$. [CrossRef]

8. Huang, P.; Huang, G.; Augenbroe, G.; Li, S. Optimal configuration of multiple-chiller plants under cooling load uncertainty for different climate effects and building types. Energy Build. 2018, 158, 684-697. [CrossRef]

9. Ho, H.C.; Knudby, A.; Sirovyak, P.; Xu, Y.; Hodul, M.; Henderson, S.B. Mapping maximum urban air temperature on hot summer days. Remote Sens. Environ. 2014, 154, 38-45. [CrossRef]

10. Chang, Y.-C.; Lin, F.-A.; Lin, C.H. Optimal chiller sequencing by branch and bound method for saving energy. Energy Convers. Manag. 2005, 46, 2158-2172. [CrossRef]

11. Chang, Y.-C.; Chan, T.-S.; Lee, W.-S. Economic dispatch of chiller plant by gradient method for saving energy. Appl. Energy 2010, 87, 1096-1101. [CrossRef]

12. Chen, C.-L.; Chang, Y.-C.; Chan, T.-S. Applying smart models for energy saving in optimal chiller loading. Energy Build. 2014, 68, 364-371. [CrossRef]

13. Chang, Y.-C. An innovative approach for demand side management-Optimal chiller loading by simulated annealing. Energy 2006, 31, 1883-1896. [CrossRef]

14. Coelho, L.d.S.; Mariani, V.C. Improved firefly algorithm approach applied to chiller loading for energy conservation. Energy Build. 2013, 59, 273-278. [CrossRef]

15. Chang, Y.-C.; Lee, C.-Y.; Chen, C.-R.; Chou, C.-J.; Chen, W.-H.; Chen, W.-H. Evolution strategy based optimal chiller loading for saving energy. Energy Convers. Manag. 2009, 50, 132-139. [CrossRef]

16. Rao, R.V. Optimization of Multiple Chiller Systems Using TLBO Algorithm. In Teaching Learning Based Optimization Algorithm; Springer: Cham, Switzerland, 2016; pp. 115-128.

17. Coelho, L.d.S.; Klein, C.E.; Sabat, S.L.; Mariani, V.C. Optimal chiller loading for energy conservation using a new differential cuckoo search approach. Energy 2014, 75, 237-243. [CrossRef]

18. Lee, W.-S.; Chen, Y.-T.; Kao, Y. Optimal chiller loading by differential evolution algorithm for reducing energy consumption. Energy Build. 2011, 43, 599-604. [CrossRef]

19. Sohrabi, F.; Nazari-Heris, M.; Mohammadi-Ivatloo, B.; Asadi, S. Optimal chiller loading for saving energy by exchange market algorithm. Energy Build. 2018, 169, 245-253. [CrossRef]

20. Cannistraro, M.; Mainardi, E.; Bottarelli, M. Testing a dual-source heat pump. Math. Model. Eng. Probl. 2018, 5, 205-210. [CrossRef] 
21. Jabari, F.; Mohammadi-Ivatloo, B. Basic Open-Source Nonlinear Mixed Integer Programming Based Dynamic Economic Dispatch of Multi-chiller Plants. In Operation, Planning, and Analysis of Energy Storage Systems in Smart Energy Hubs; Springer: Cham, Switzerland, 2018; pp. 121-127.

22. Chang, Y.-C.; Lin, J.-K.; Chuang, M.-H. Optimal chiller loading by genetic algorithm for reducing energy consumption. Energy Build. 2005, 37, 147-155. [CrossRef]

23. Chang, Y.-C. Genetic algorithm based optimal chiller loading for energy conservation. Appl. Therm. Eng. 2005, 25, 2800-2815. [CrossRef]

24. Lo, C.-C.; Tsai, S.-H.; Lin, B.-S. Economic dispatch of chiller plant by improved ripple bee swarm optimization algorithm for saving energy. Appl. Therm. Eng. 2016, 100, 1140-1148. [CrossRef]

25. Zheng, Z.-X.; Li, J.-Q. Optimal chiller loading by improved invasive weed optimization algorithm for reducing energy consumption. Energy Build. 2018, 161, 80-88. [CrossRef]

26. Saeedi, M.; Moradi, M.; Hosseini, M.; Emamifar, A.; Ghadimi, N. Robust optimization based optimal chiller loading under cooling demand uncertainty. Appl. Ther. Eng. 2019, 148, 1081-1091. [CrossRef]

27. Piccolo, A.; Siclari, R.; Rando, F.; Cannistraro, M. Comparative performance of thermoacoustic heat exchangers with different pore geometries in oscillatory flow. Implementation of experimental techniques. Appl. Sci. 2017, 7, 784. [CrossRef]

28. Cannistraro, M.; Castelluccio, M.E.; Germanò, M. New sol-gel deposition technique in the Smart-Windows-Computation of possible applications of Smart-Windows in buildings. J. Build. Eng. 2018, 19, 295-301. [CrossRef]

29. Generalized Algebraic Mathematical Modeling Systems. Available online: https://www.gams.com/ (accessed on 17 July 2015).

30. Available online: https://www.gams.com/latest/docs/S_BARON.html (accessed on 5 June 2015).

31. Lin, W.-M.; Tu, C.-S.; Tsai, M.-T.; Lo, C.-C. Optimal energy reduction schedules for ice storage air-conditioning systems. Energies 2015, 8, 10504-10521. [CrossRef]

32. Soroudi, A. Power System Optimization Modeling in GAMS; Springer: Cham, Switzerland, 2017.

(C) 2019 by the authors. Licensee MDPI, Basel, Switzerland. This article is an open access article distributed under the terms and conditions of the Creative Commons Attribution (CC BY) license (http://creativecommons.org/licenses/by/4.0/). 